\title{
Is there still a place for vasopressors in the treatment of cardiac arrest?
}

\author{
Claudio Sandroni*, Fabio Cavallaro and Massimo Antonelli \\ This article is one of eleven reviews selected from the Annual Update in Intensive Care and Emergency Medicine 2012 (Springer Verlag, \\ DOI: 10.1007/978-3-642-25716-2) and co-published as a series in Critical Care. Other articles in the series can be found online at \\ http://ccforum.com/series/annualupdate2012. Further information about the Annual Update in Intensive Care and Emergency Medicine is \\ available from http://www.springer.com/series/8901.
}

\begin{abstract}
Introduction
Around 300,000 people in the United States experience an out-of-hospital cardiac arrest each year, and less than $10 \%$ of them survive to hospital discharge [1]. Survival is only slightly better for in-hospital cardiac arrest [2]. While provision of basic measures like bystander cardiopulmonary resuscitation (CPR) or early defibrillation is consistently associated with better survival [3], the benefit of advanced life support (ALS) measures, such as ventilation with advanced airway and administration of drugs, has not been clearly demonstrated [4].

Among drugs, after the recent removal of atropine from ALS protocols [5], and considering that antiarrhythmics are recommended only for the minority of cardiac arrest patients with persistent ventricular fibrillation/ventricular tachycardia (VF/VT), the mainstay of drug therapy for cardiac arrest is represented by vasopressors, namely epinephrine or vasopressin.
\end{abstract}

\section{Rationale for the use of vasopressors in cardiac arrest}

During cardiovascular collapse following cardiac arrest, flow to vital organs decreases to zero. CPR partially restores this blood flow, but cardiac output remains low, about $20 \%$ of its normal value. The blood flow to the heart is driven by the coronary perfusion pressure, defined as the difference between the aortic diastolic pressure and the right atrial pressure. The importance of maintaining an adequate coronary perfusion pressure during CPR has been highlighted in animal and human studies. Kern et al. [6] showed that a coronary perfusion pressure $<20 \mathrm{mmHg}$ measured after 20 minutes of CPR

\footnotetext{
*Correspondence: sandroni@rm.unicatt.it

Department of Anaesthesiology and Intensive Care, Catholic University School of Medicine, Rome, Italy
}

was associated with poor survival in dogs with VF. Brown et al. [7] found a positive association between myocardial blood flow and defibrillation rates in a swine model of VF. These results were confirmed in adult cardiac arrest patients by Paradis and colleagues [8], who found that initial and maximal coronary perfusion pressure values were significantly higher in patients who attained recovery of spontaneous circulation (ROSC) versus those with no ROSC. No patient whose coronary perfusion pressure was below $15 \mathrm{mmHg}$ was resuscitated.

Vasopressor drugs increase coronary perfusion pressure by increasing aortic diastolic pressure and also increase systemic vascular resistance (SVR), diverting blood flow from peripheral to vital organs. Animal studies [6,7] have demonstrated that epinephrine increases both myocardial and cerebral blood flow during CPR, and facilitates ROSC.

\section{Epinephrine}

Epinephrine has been the standard vasopressor in cardiac arrest for more than 30 years. The current European Resuscitation Council (ERC) guidelines for ALS [5] recommend epinephrine at a dose of $1 \mathrm{mg}$ to be administered as soon as possible in patients with asystole or pulseless electrical activity, or after three unsuccessful defibrillation shocks in those with VF/VT. Similar recommendations are made by the American Heart Association (AHA) [9]. During CPR, epinephrine should be repeated every 3 to 5 minutes, because of its short half-life.

The pharmacological effects of epinephrine are mediated by the $\alpha$ and $\beta$ adrenergic receptors. The $\alpha$-receptors mediate mainly vasoconstriction, while $\beta$-receptors are responsible for stimulating effects on the heart $\left(\beta_{1}\right)$ along with vasodilatation in some vascular beds $\left(\beta_{2}\right)$ [10]. The vasoconstrictor $\alpha$ effect represents the scope of the administration of epinephrine during CPR, whereas 
cardiac stimulation from $\beta$ effects is not beneficial in this context, because the heart is not contracting and cardiac output depends essentially on chest compression. In fact, $\beta$ effects increase myocardial oxygen consumption and may cause an imbalance between oxygen demand and supply in the heart tissue. In an animal model, Ditchey and Lindenfeld [11] demonstrated that the administration of intravenous epinephrine during CPR significantly increased not only left ventricular (LV) coronary blood flow but also myocardial lactate concentration. $\beta$-adrenergic inotropic and chronotropic actions of epinephrine are mediated by calcium channel opening and calcium influx into the heart cells [12]. However, calcium ions are also intracellular mediators of ischemic damage [13].

There is evidence that the $\beta_{1}$ effects of epinephrine worsen post-resuscitation myocardial dysfunction. This effect consists of a transient reduction in myocardial performance from pre-arrest levels, which is commonly observed after ROSC [14]. In a study by Laurent et al. [15], post-resuscitation myocardial dysfunction occurred in 73/165 (44\%) patients resuscitated from out of-hospital cardiac arrest. Persistent dysfunction was associated with early death from multiorgan failure. In an experimental model of cardiac arrest and resuscitation, Tang et al. [16] demonstrated that post-resuscitation myocardial dysfunction was more severe in animals treated with epinephrine than in those treated with the $\alpha$-agonist, phenylephrine, or with a combination of epinephrine and the $\beta_{1}$-blocker, esmolol, thus suggesting that $\beta_{1}$ stimulation has a role in determining this phenomenon.

Recent experimental evidence shows that, despite an increase in cerebral perfusion pressure, epinephrine can reduce cerebral tissue perfusion. In a pig model of cardiac arrest, Ristagno et al. [17] measured the cerebral microcirculatory blood flow, using orthogonal polarization spectral (OPS) imaging, and the cerebral cortical $\mathrm{CO}_{2}$ and $\mathrm{O}_{2}$ tensions $\left(\mathrm{PbO}_{2}\right.$ and $\left.\mathrm{PbCO}_{2}\right)$ during and after $\mathrm{CPR}$. Animals were randomized to either epinephrine or a combination of epinephrine with $\alpha_{1}$ - and $\beta$-receptor blockade (prazosin + propranolol) or a combination of epinephrine with $\alpha_{2}$ and $\beta$ receptor blockade (yohimbine + propranolol). Results showed that administration of epinephrine alone was associated with a significant reduction in post-resuscitation cerebral microcirculation and $\mathrm{PbO}_{2}$, and with a significant increase in $\mathrm{PbCO}_{2}$. The phenomenon was reduced after combined $\alpha_{1}$ and $\beta$ blockade but persisted after $\alpha_{2}$ plus $\beta$ blockade. The authors attributed this effect of epinephrine to smallvessel constriction, probably mediated by activation of the $\alpha_{1}$ receptor subtype on cerebral and pial arterioles.

\section{Vasopressin}

Vasopressin is an endogenous nonapeptide that is synthesized by neurons of the supraoptic and paraventricular nuclei of the hypothalamus and is released in the posterior part of the pituitary gland. In normal conditions, vasopressin is released in response to decreased blood volume or increased plasma osmolality. Three types of vasopressin receptors have been identified: V1, V2 and V3. Whereas the V2 receptors mediate water reabsorption and V3 mediate the effects of vasopressin on central nervous system, the V1 receptors mediate cardiovascular effects, consisting of skin, skeletal muscle and splanchnic blood vessel vasoconstriction.

Vasopressin has been proposed as an alternative to epinephrine in cardiac arrest, based on the finding that its levels were significantly higher in successfully resuscitated patients than in patients who died [18]. In comparison with epinephrine, vasopressin has several advantages: First, its V1-mediated effects increase arterial peripheral resistance without causing direct myocardial stimulation. Moreover, it has a longer half-life (1020 minutes vs. $3-5$ minutes) and is more resistant to acidosis [19].

A series of animal studies were conducted on vasopressin during CPR. These studies consistently demonstrated that vasopressin doses between 0.4 and $0.8 \mathrm{U} / \mathrm{kg}$ led to a significantly higher coronary perfusion pressure and myocardial blood flow than epinephrine and were associated with a higher percentage of successfully resuscitated animals [20-23]. However, adverse cardiovascular effects from vasopressin have been described as well. They are related to the persistent vasoconstriction and increased myocardial afterload induced by this drug. In an observational study on patients with cirrhosis who received intravenous vasopressin during portacaval shunt operation [24], 13 of 52 patients developed signs of myocardial ischemia requiring treatment with vasodilators. In a pig model of prolonged VF [25], vasopressin was associated with significantly higher SVR and blood pressure after ROSC but also with a significantly lower cardiac index and contractility when compared with epinephrine, although survival at $24 \mathrm{~h}$ was not affected.

\section{Epinephrine versus vasopressin: results of clinical trials}

A series of clinical trials comparing vasopressin with epinephrine was conducted between 1997 and 2009 (Table 1). In a first small randomized trial on 40 prehospital patients who had not responded to three consecutive defibrillation shocks, the administration of $40 \mathrm{IU}$ of vasopressin versus $1 \mathrm{mg}$ of epinephrine was associated with a $50 \%$ increase in survival to hospital admission and to a $66 \%$ increase of survival at 24 hours [26]. However, a subsequent randomized placebo-controlled trial on 200 adult in-hospital patients comparing the same doses as in the previous study did not confirm those results [27]. In fact, 40 (39\%) patients in the 
Table 1. Summary of the characteristics of the clinical trials that have compared vasopressin with epinephrine in cardiac arrest

\begin{tabular}{lccll}
\hline Author, year [ref] & Setting & $\begin{array}{c}\text { Number of } \\
\text { enrolled } \\
\text { patients }\end{array}$ & Intervention & $\begin{array}{c}\text { Mean time to first } \\
\text { vasopressin bolus, min }\end{array}$ \\
\hline Lindner, 1997 [26] & OHCA & 40 & Vasopressin 40 IU followed by epinephrine & 13.9 \\
Stiell, 2001 [27] & IHCA & 200 & Vasopressin 40 IU followed by epinephrine & 6.7 \\
Wenzel, 2004 [29] & OHCA & 1186 & Vasopressin 40 IU for up to 2 cycles, followed by epinephrine & 17.5 \\
Gueugniaud, 2008 [30] & OHCA & 2894 & $\begin{array}{l}\text { Vasopressin 40 IU plus epinephrine for up to 2 cycles, } \\
\text { followed by epinephrine }\end{array}$ & 21.4 \\
Mentzelopoulos, 2009 [31] & IHCA & 100 & $\begin{array}{l}\text { Vasopressin 20 IU plus epinephrine for up to 5 cycles, plus } \\
\text { methylprednisolone 40 mg (once only) }\end{array}$ & $<5$ \\
\hline
\end{tabular}

Treatment in the control group was epinephrine in all studies. IHCA, in-hospital cardiac arrest; IU, International Units; OHCA, out of-hospital cardiac arrest.

vasopressin group versus 34 (35\%) patients in the epinephrine group survived 1 hour ( $p=0.66 ; 95 \%$ confidence interval $[\mathrm{CI}]$ for absolute increase in survival: $-10.9 \%$ to $17.0 \%)$ whereas $12(12 \%)$ versus $13(14 \%)$ patients, respectively, survived to hospital discharge ( $\mathrm{p}=0.67 ; 95 \% \mathrm{CI}-11.8 \%$ to $7.8 \%$ ). In this study, vasopressin and epinephrine were randomized only at the first bolus, and epinephrine was given as subsequent boluses to all patients. This single and early administration of vasopressin has been criticized because, according to animal studies, vasopressin appears to be more beneficial in conditions of severe acidosis and, therefore, at a later phase of resuscitation [28].

A subsequent randomized controlled trial [29] enrolled 1186 out-of-hospital cardiac arrest patients to receive either $40 \mathrm{IU}$ of vasopressin or $1 \mathrm{mg}$ of epinephrine during two consecutive ALS cycles, followed by additional boluses of epinephrine if needed. The study demonstrated no significant differences in outcome between the two groups, except for the subgroup of patients with asystole, in whom survival to both hospital admission and hospital discharge were significantly higher with vasopressin (76/262 [29.0\%] vs. 54/266 [20.3\%]; p $=0.02$ and $2 / 257$ [4.7\%] vs. $4 / 262$ [1.5\%] $\mathrm{p}=0.04$, respectively); however, the number of patients who survived to discharge in that group was negligible. In a post-hoc analysis of patients with prolonged cardiac arrest in whom additional doses of epinephrine were needed, vasopressin was associated with higher survival both to admission and to discharge, although patients who were given vasopressin had higher rates of poor neurological outcome (10/20 [50\%] vs. 1/5 [20\%]). Again, the effect was particularly evident in patients with asystole. Being the results of a post-hoc analysis, these data lack statistical power and are subject to bias.

To investigate the potential synergistic effects of vasopressin plus epinephrine, a larger, multicenter placebocontrolled study was carried out on 2894 out-of-hospital cardiac arrest patients who were randomized to receive either $1 \mathrm{mg}$ of epinephrine plus $40 \mathrm{IU}$ of vasopressin or epinephrine alone. In both groups, additional epinephrine was given if needed [30]. Unfortunately, the study did not show any differences between the two interventions in terms of ROSC (28.6\% vs. $29.5 \%$; relative risk, 1.01; $95 \%$ CI 0.97 to 1.06), survival to hospital admission (20.7\% vs. 21.3\%; relative risk of death, 1.01; 95\% CI 0.97 to 1.05$)$, or survival to hospital discharge (1.7\% vs. $2.3 \%$; relative risk, $1.01 ; 95 \%$ CI 1.00 to 1.02 ). The rates of good neurological recovery were also similar in the two groups. The study included a high percentage of patients with asystole $(82.4 \%)$, which made it very suitable for investigating the possible benefit of vasopressin in that specific group suggested by the previous study.

In a recent single center placebo-controlled trial [31], 100 consecutive patients with in-hospital cardiac arrest were randomized to receive either $1 \mathrm{mg}$ epinephrine or epinephrine plus 20 IU vasopressin per resuscitation cycle for the first five cycles, followed by additional epinephrine if needed. Based on the results of previous observational studies which documented low cortisol levels in patients resuscitated from cardiac arrest, the intervention group received $40 \mathrm{mg}$ methylprednisolone sodium succinate during the first resuscitation cycle. In addition, resuscitated patients with clinical signs of shock in the study group were treated with hydrocortisone sodium succinate at a dose of $300 \mathrm{mg} /$ day for a maximum of seven days. Results showed that the experimental group had significantly higher rates of ROSC (39/48 [81\%] vs. 27/52 [52\%]; $\mathrm{p}=0.003$ ) and survival to hospital discharge $9 / 48$ [19\%] vs. $2 / 52$ [4\%]; $p=0.02$ ). In 31 patients an arterial line was in place when cardiac arrest occurred; among those patients, systolic, diastolic and mean arterial blood pressures were significantly higher in the intervention group both during CPR and after ROSC. Moreover, vasopressor use during follow-up was significantly lower in the intervention group $(\mathrm{p}=0.002)$.

The above study was undertaken in the hospital environment, where several patients had venous access in 
place $36 \%$ of cardiac arrests occurred in the intensive care unit $[\mathrm{ICU}]$ or in the operating room $[\mathrm{OR}]$ ) and response times were relatively short [32]. For this reason, the administration of the study drug occurred in less than 5 minutes, much earlier than in other trials. Another feature was the high dosage of vasopressin (mean 73.3 [ \pm 30.1$]$ IU, range 20-100 IU) administered to the intervention group. Unfortunately, because of the study design, the effects of vasopressin and those of steroids could not be analyzed separately.

A very recent meta-analysis [33] summarized the results of clinical trials on vasopressin for cardiac arrest. It included 4475 patients from six randomized controlled trials published between 1997 and 2009. In all trials, vasopressin was compared with epinephrine. The authors carried out subgroup analyses according to the initial cardiac rhythm and time from collapse to drug administration. Results showed that vasopressin did not improve overall rates of ROSC, long-term survival, or favorable neurological outcome. In the subgroup of patients with asystole in whom the time to drug administration was shorter than 20 minutes, vasopressin was associated with a significantly higher rate of both ROSC and long-term survival (OR 1.70 [95\% CI 1.17-2.47], $\mathrm{p}=0.005$, and OR 2.84 [95\% CI 1.19-6.79], $\mathrm{p}=0.02$, respectively). However, this subgroup included only 27 patients (20 in the vasopressin group and 7 in the control group) from three different trials. No data on favorable neurological outcome are available for this subgroup. In contrast to what has been hypothesized by other authors [28] these results seem to suggest that the effects of vasopressin are more beneficial when it is administered early.

Based on the neutral results of clinical trials, the 2010 Guidelines for Adult Advanced Cardiovascular Life Support of the AHA [9] recommended vasopressin as an alternative to the first or the second dose of epinephrine, at a dose of 40 IU via either intravenous or intraosseous routes. Arginine vasopressin is not or is scarcely available in some European Countries. The ERC 2010 Guidelines for Resuscitation did not make any specific recommendation on vasopressin and refer uniquely to epinephrine as the standard vasopressor drug for cardiac arrest [5].

\section{Drugs versus no drugs}

During recent years, the limited evidence in favor of ALS measures and the evidence of possible harm from epinephrine in the post-resuscitation phase have raised concern as to whether drugs should be used at all during cardiac arrest. To address this point, a trial was conducted by Olasveengen et al. in Norway and its results published on 2009 [34]. In this study, 851 patients were randomized to receive ALS with or without intravenous drug administration. In the no-drug group, venous access and drugs were only allowed 5 minutes after ROSC (Table 2). To assess a possible interference from venous access, which is a time-consuming procedure that could divert focus from good-quality resuscitation, CPR quality was monitored using transthoracic impedance. Measures of CPR quality, such as time without compressions, CPR pauses before defibrillation shocks, compression rate and ventilation rate, were calculated. A special characteristic of this trial was that resuscitation was performed according to a local protocol that included three minutes of CPR both before defibrillation and between subsequent shocks in patients with VF (instead of no CPR before defibrillation and two minutes of CPR between subsequent shocks, as in the standard ALS Guidelines).

Results showed that survival to hospital discharge did not differ significantly between the groups, despite a small trend in favor of the drug group $(10.5 \%$ vs. $9.2 \%$, OR 1.16 [95\%CI 0.74-1.82], $\mathrm{p}=0.61$ ). Patients in the drug group had significantly higher rates of ROSC $(40 \%$ vs. $25 \%$, OR 1.99 [95\%CI 1.48-2.67], p 0.001), and had longer CPR attempts, during which a higher number of defibrillation shocks were given. There were no differences in the causes of ICU deaths, most of which (69.5\%) were due to brain damage, and no differences in neurological outcome between the two groups were observed. The results of the Olasveengen study [34] suggest that in adults with out-of-hospital cardiac arrest, the administration of drugs does not improve any relevant outcomes, except short-term survival. However, the study was not specifically focused on vasopressors. Epinephrine was administered in $79 \%$ of patients in the drug group but its specific clinical effect could not be assessed separately. Moreover, the intervention could not be blinded for obvious reasons.

A very recent single center, randomized, double-blind, placebo-controlled trial by Jacobs et al. [35] was specifically designed to assess the effects of administration of epinephrine on survival from cardiac arrest (Table 2). The study included 534 adult patients (out of the planned 4426) with out-of-hospital cardiac arrest from any cause who were randomized to receive either epinephrine $1 \mathrm{mg}$ or placebo. No other drug was used during ALS. Study drug and placebo were administered at the same time intervals recommended in the ALS guidelines and were repeated up to a maximum of 10 times. Patients in VF/VT who responded early to defibrillation were not randomized.

The results of the study showed that, after adjustment for confounding variables, patients in the epinephrine group had a significantly higher likelihood of achieving ROSC (23.5\% vs. 8.4\%; OR 3.5 [95\% CI 2.1-6.0]) and more than twice the odds of surviving to hospital discharge, although the difference was not significant (4.0\% vs. $1.9 \%$; OR 2.1 [0.7-6.3]). The study was largely 
Table 2. Methodological features and results of recent clinical trials comparing advanced life support treatment with or without drugs

\begin{tabular}{|c|c|c|c|c|c|c|c|c|}
\hline \multirow[b]{2}{*}{$\begin{array}{l}\text { Author, } \\
\text { year [ref] }\end{array}$} & \multirow[b]{2}{*}{ Study design } & \multirow{2}{*}{$\begin{array}{l}\text { Actual/ } \\
\text { planned } \\
\text { sample } \\
\text { size (\%) }\end{array}$} & \multirow{2}{*}{$\begin{array}{l}\text { Treatment in the } \\
\text { intervention group }\end{array}$} & \multirow[b]{2}{*}{$\begin{array}{l}\text { Treatment in the } \\
\text { control group }\end{array}$} & \multirow{2}{*}{$\begin{array}{l}\text { Controlled } \\
\text { for CPR } \\
\text { quality }\end{array}$} & \multirow{2}{*}{$\begin{array}{c}\text { Causes } \\
\text { of death } \\
\text { documented }\end{array}$} & \multicolumn{2}{|c|}{ Survival (\%) } \\
\hline & & & & & & & ROSC & Discharge \\
\hline $\begin{array}{l}\text { Olasveengen, } \\
2009[34]\end{array}$ & $\begin{array}{l}\text { Randomized, } \\
\text { open-label }\end{array}$ & $\begin{array}{l}851 / 900 \\
(94.6 \%)\end{array}$ & $\begin{array}{l}\text { Epinephrine, amiodarone, } \\
\text { atropine }\end{array}$ & $\begin{array}{l}\text { No drug or venous access } \\
\text { up to } 5 \text { minutes after ROSC }\end{array}$ & Yes & Yes & 26.1 & 9.9 \\
\hline $\begin{array}{l}\text { Jacobs, } \\
2011[35]\end{array}$ & $\begin{array}{l}\text { Randomized, } \\
\text { double-blind } \\
\text { placebo-controlled }\end{array}$ & $\begin{array}{l}534 / 4426 \\
(12.1 \%)\end{array}$ & Epinephrine & Intravenous placebo & No & No & 16.1 & 3.0 \\
\hline
\end{tabular}

CPR, cardiopulmonary resuscitation; ROSC, recovery of spontaneous circulation.

underpowered, having recruited only $12 \%$ of the planned sample. This was mainly due to ethical concerns, which prevented four of the five ambulance services that had been initially involved from continuing the study. Funding restrictions and final expiry of the study drug were additional issues. The trial confirmed that ALS drugs, especially vasopressors, significantly increase ROSC rates in adults with out-of-hospital cardiac arrest. There was also a clear trend towards an increased survival to hospital discharge. The main limitation of the trial was the limited sample size, because of its failure to achieve full patient recruitment. Another limitation was that the study did not control for CPR quality, although its placebo-controlled design probably prevented imbalances in CPR quality among the study groups.

\section{Vasopressors for cardiac arrest: benefit or harm?}

Results of recent clinical trials indicate that use of vasopressors during cardiac arrest increases the rate of successful resuscitation, and this effect is somewhat expected since they increase organ perfusion during CPR. However, there is no definite evidence that vasopressors increase either survival to discharge or neurological prognosis. There are three possible explanations for this:

- A first explanation could be that vasopressors restore spontaneous circulation in patients who are simply 'too ill to survive' and who die as soon as the temporary effect of resuscitation maneuvers and drugs has finished. This would confirm the results of the observational Ontario Prehospital Advanced Life Support (OPALS) study [4], which showed no improvement of survival to discharge when ALS was added to basic life support in an emergency medical system. In this case, vasopressors would just provide futile cardiac resuscitation to patients destined to die shortly afterwards from irreversible organ damage.

- However, it is also possible that patients resuscitated because of the extra benefit of vasopressors are potentially salvageable with the improvement or better implementation of post-resuscitation care. Most patients who die in the ICU after having been resuscitated from cardiac arrest do so from neurological causes [34, 36]. Mild therapeutic hypothermia can reduce postanoxic brain damage and improve survival to hospital discharge and neurological outcome after cardiac arrest $[37,38]$. However, recent surveys showed that implementation of mild therapeutic hypothermia in many ICUs in the Western world is still incomplete $[39,40]$. Rigorous application of post-resuscitation bundles [41] and triage of resuscitated patients towards specialized cardiac arrest centers where optimal postresuscitation care is provided [42] represent possible resources to improve prognosis of resuscitated patients in the near future.

- A third explanation could be that vasopressors increase the success rate of cardiac resuscitation because they improve coronary perfusion but also reduce the chances of survival for many resuscitated patients because of their side effects, such as increased postresuscitation myocardial dysfunction or decreased cerebral microcirculation. However, in the Olasveengen trial [34], distribution of the causes of death was similar in the group that received vasopressors and in the group that received no drug. A second potential indirect harmful effect of vasopressors could be their interference with the resuscitation process, introducing delays in CPR for drug preparation and intravenous access, and diverting team resources from more important tasks. However, the Olasveengen trial did not demonstrate any delay or deterioration in CPR quality in the drug versus no-drug groups.

\section{Conclusion}

The role of vasopressors during resuscitation from cardiac arrest needs to be further investigated. In experimental models, vasopressors increase diastolic blood pressure and blood flow to vital organs during CPR and facilitate resuscitation but also have detrimental effects on post-resuscitation myocardial performance and cerebral circulation. Two recent controlled trials in out-ofhospital cardiac arrest patients demonstrated that administration of epinephrine and other drugs was associated with a significant increase in short-term survival but not in survival to hospital discharge. In one of those 
trials, patients in the epinephrine group had more than twice the odds of surviving to hospital discharge than those who received placebo, but the difference did not reach statistical significance, possibly because of inadequate sample size. Future placebo-controlled trials on larger populations are needed to assess more clearly the association between epinephrine and survival to hospital discharge. Clinical studies are also needed to investigate the occurrence of side effects from vasopressors in humans after resuscitation and their possible influence on hospital survival. At present, epinephrine is the most widely used vasopressor in advanced life support. To date, no advantage from the use of vasopressin rather than epinephrine in any of the relevant outcomes from cardiac arrest has been identified in clinical studies.

\section{Abbreviations}

AHA, American Heart Association; ALS, advanced life support; Cl, confidence interval; CPR, cardiopulmonary resuscitation; ERC, European Resuscitation Council; ICU, intensive care unit; IHCA, in-hospital cardiac arrest; IU, International Units; LV, left ventricular; OHCA, out-of-hospital cardiac arrest; OPALS, Ontario Prehospital Advanced Life Support; OPS, orthogonal polarization spectral; OR, operating room; ROSC, recovery of spontaneous circulation; SVR, systemic vascular resistance; VFNT, ventricular fibrillation/ ventricular tachycardia.

\section{Competing interests}

The authors declare there are no competing interests.

Published: 20 March 2012

\section{References}

1. McNally B, Robb R, Mehta M, et al:: Out-of-Hospital Cardiac Arrest Surveillance - Cardiac Arrest Registry to Enhance Survival (CARES), United States, October 1, 2005-December 31, 2010. MMWR Surveill Summ 2011 60(8):1-19.

2. Sandroni C, Nolan J, Cavallaro F, Antonelli M: In-hospital cardiac arrest: incidence, prognosis and possible measures to improve survival. Intensive Care Med 2007, 33:237-245.

3. Sasson C, Rogers MA, Dahl J, Kellermann AL: Predictors of survival from out-of-hospital cardiac arrest: a systematic review and meta-analysis. Circ Cardiovasc Qual Outcomes 2010, 3:63-81.

4. Stiell IG, Wells GA, Field B, et al:: Advanced cardiac life support in out-ofhospital cardiac arrest. N Engl J Med 2004, 351:647-656.

5. Deakin CD, Nolan JP, Soar J, et al.: European Resuscitation Council Guidelines for Resuscitation 2010 Section 4. Adult advanced life support. Resuscitation 2010, 81:1305-1352.

6. Kern KB, Ewy GA, Voorhees WD, Babbs CF, Tacker WA: Myocardial perfusion pressure: a predictor of 24-hour survival during prolonged cardiac arrest in dogs. Resuscitation 1988, 16:241-250.

7. Brown CG, Katz SE, Werman HA, Luu T, Davis EA, Hamlin RL: The effect of epinephrine versus methoxamine on regional myocardial blood flow and defibrillation rates following a prolonged cardiorespiratory arrest in a swine model. Am J Emerg Med 1987, 5:362-369.

8. Paradis NA, Martin GB, Rivers EP, et al:: Coronary perfusion pressure and the return of spontaneous circulation in human cardiopulmonary resuscitation. JAMA 1990, 263:1106-1113.

9. Neumar RW, Otto CW, Link MS, et al.: Part 8: adult advanced cardiovascular life support: 2010 American Heart Association Guidelines for Cardiopulmonary Resuscitation and Emergency Cardiovascular Care. Circulation 2010, 122:S729-S767.

10. Schumann $\mathrm{HJ}$ : What role do alpha- and beta-adrenoceptors play in the regulation of the heart? Eur Heart J 1983, 4(Suppl A):55-60.

11. Ditchey RV, Lindenfeld J: Failure of epinephrine to improve the balance between myocardial oxygen supply and demand during closed-chest resuscitation in dogs. Circulation 1988, 78:382-389.
12. Brown AM, Birnbaumer L: Direct $G$ protein gating of ion channels. Am J Physiol 1988, 254:H401-H410.

13. Meissner A, Morgan JP: Contractile dysfunction and abnormal Ca2+ modulation during postischemic reperfusion in rat heart. Am J Physiol 1995, 268:H100-H111.

14. Gonzalez MM, Berg RA, Nadkarni VM, et al:: Left ventricular systolic function and outcome after in-hospital cardiac arrest. Circulation 2008, 117:1864-1872.

15. Laurent I, Monchi M, Chiche JD, et al:: Reversible myocardial dysfunction in survivors of out-of-hospital cardiac arrest. J Am Coll Cardiol 2002, 40:2110-2116.

16. Tang W, Weil MH, Sun S, Noc M, Yang L, Gazmuri RJ: Epinephrine increases the severity of postresuscitation myocardial dysfunction. Circulation 1995, 92:3089-3093.

17. Ristagno G, Tang W, Huang $L$, et al.: Epinephrine reduces cerebral perfusion during cardiopulmonary resuscitation. Crit Care Med 2009, 37:1408-1415.

18. Lindner $\mathrm{KH}$, Strohmenger HU, Ensinger $\mathrm{H}$, Hetzel WD, Ahnefeld FW, Georgieff M: Stress hormone response during and after cardiopulmonary resuscitation. Anesthesiology 1992, 77:662-668.

19. Zhong JQ, Dorian P: Epinephrine and vasopressin during cardiopulmonary resuscitation. Resuscitation 2005, 66:263-269.

20. Krismer AC, Lindner KH, Wenzel V, et al.: The effects of endogenous and exogenous vasopressin during experimental cardiopulmonary resuscitation. Anesth Analg 2001, 92:1499-1504.

21. Lindner KH, Prengel AW, Pfenninger EG, et al:: Vasopressin improves vital organ blood flow during closed-chest cardiopulmonary resuscitation in pigs. Circulation 1995, 91:215-221.

22. Wenzel V, Lindner KH, Krismer AC, Miller EA, Voelckel WG, Lingnau W: Repeated administration of vasopressin but not epinephrine maintains coronary perfusion pressure after early and late administration during prolonged cardiopulmonary resuscitation in pigs. Circulation 1999, 99:1379-1384.

23. Wenzel V, Lindner KH, Prengel AW, et al:: Vasopressin improves vital organ blood flow after prolonged cardiac arrest with postcountershock pulseless electrical activity in pigs. Crit Care Med 1999, 27:486-492.

24. Sirinek KR, Adcock DK, Levine BA: Simultaneous infusion of nitroglycerin and nitroprusside to offset adverse effects of vasopressin during portosystemic shunting. Am J Surg 1989, 157:33-37.

25. Prengel AW, Lindner KH, Keller A, Lurie KG: Cardiovascular function during the postresuscitation phase after cardiac arrest in pigs: a comparison of epinephrine versus vasopressin. Crit Care Med 1996, 24:2014-2019.

26. Lindner KH, Dirks B, Strohmenger HU, Prengel AW, Lindner IM, Lurie KG: Randomised comparison of epinephrine and vasopressin in patients with out-of-hospital ventricular fibrillation. Lancet 1997, 349:535-537.

27. Stiell IG, Hebert PC, Wells GA, et al:: Vasopressin versus epinephrine for inhospital cardiac arrest: a randomised controlled trial. Lancet 2001, 358:105-109.

28. Wenzel $\mathrm{V}$, Lindner $\mathrm{KH}$ : Vasopressin and epinephrine for cardiac arrest. Lancet 2001, 358:2080-2081.

29. Wenzel V, Krismer AC, Arntz HR, Sitter H, Stadlbauer KH, Lindner KH: A comparison of vasopressin and epinephrine for out-of-hospital cardiopulmonary resuscitation. N Engl J Med 2004, 350:105-113.

30. Gueugniaud PY, David JS, Chanzy E, et al:: Vasopressin and epinephrine vs. epinephrine alone in cardiopulmonary resuscitation. N Engl J Med 2008, 359:21-30.

31. Mentzelopoulos SD, Zakynthinos SG, Tzoufi M, et al:: Vasopressin, epinephrine, and corticosteroids for in-hospital cardiac arrest. Arch Intern Med 2009, 169:15-24.

32. Sandroni C, Cavallaro F, Ferro G, et al:: A survey of the in-hospital response to cardiac arrest on general wards in the hospitals of Rome. Resuscitation 2003, 56:41-47.

33. Mentzelopoulos SD, Zakynthinos SG, Siempos I, Malachias S, Ulmer H, Wenzel $\mathrm{V}$ : Vasopressin for cardiac arrest: meta-analysis of randomized controlled trials. Resuscitation 2011, 83:32-39.

34. Olasveengen TM, Sunde K, Brunborg C, Thowsen J, Steen PA, Wik L: Intravenous drug administration during out-of-hospital cardiac arrest: a randomized trial. JAMA 2009, 302:2222-2229.

35. Jacobs IG, Finn JC, Jelinek GA, Oxer HF, Thompson PL: Effect of adrenaline on survival in out-of-hospital cardiac arrest: a randomised double-blind placebo-controlled trial. Resuscitation 2011, 82:1138-1143.

36. Laver S, Farrow C, Turner D, Nolan J: Mode of death after admission to an 
intensive care unit following cardiac arrest. Intensive Care Med 2004 30:2126-2128.

37. Bernard SA, Gray TW, Buist MD, et al:: Treatment of comatose survivors of out-of-hospital cardiac arrest with induced hypothermia. N Engl J Med 2002, 346:557-563.

38. The Hypothermia After Cardiac Arrest Study Group: Mild therapeutic hypothermia to improve the neurologic outcome after cardiac arrest. $N$ Engl J Med 2002, 346:549-556.

39. Merchant RM, Soar J, Skrifvars MB, et al.: Therapeutic hypothermia utilization among physicians after resuscitation from cardiac arrest. Crit Care Med 2006, 34:1935-1940.

40. Binks AC, Murphy RE, Prout RE, et al.: Therapeutic hypothermia after cardiac arrest - implementation in UK intensive care units. Anaesthesia 2010, 65:260-265
41. Stub D, Bernard S, Duffy SJ, Kaye DM: Post cardiac arrest syndrome: a review of therapeutic strategies. Circulation 2011, 123:1428-1435.

42. Soar J, Packham S: Cardiac arrest centres make sense. Resuscitation 2010, 81:507-508

doi:10.1186/cc11227

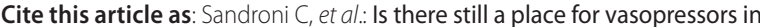
the treatment of cardiac arrest? Critical Care 2012, 16:213. 